\title{
A pedagoxía narrativa como elemento de avaliación da aprendizaxe clínica no grao de Enfermaría
}

\author{
Maria-Jesus Movilla-Fernandez, Emma Rodríguez-Maseda, Carla \\ Freijomil-Vázquez, Sara Fernández-Basanta \\ Departamento Ciencias da Saúde. Universidade da Coruña
}

\section{RESUMO}

Na materia de Practicum do Grao de Enfermería empregase a pedagoxía narrativa, que consiste en que os estudantes elaboran 3 entradas de un diario reflexivo sobre as experiencias de aprendizaxe no entorno clínico. Durante 0 curso 2017/2018, un grupo de profesoras de esta materia teñen o obxectivo de identificar elementos que os estudantes experimentan como relevantes nas súas entradas no diario reflexivo no relativo a súa aprendizaxe clínica no momento do Practicum. Empregouse unha análise cualitativa do discurso das tres entradas no diario reflexivo de 20 estudantes. As categorías de significado que emerxeron foron: "experiencias aprendizaxe negativas", "experiencias aprendizaxe positivas" e "querer aprender versus aprender sen querer". Concluímos que as narrativas das experiencias dos estudantes infórmanos sobre aspectos que condicionan a súa aprendizaxe, e que nos trasladamos a unha mellora do proceso de aprendizaxe e da avaliación, mediante a comparativa das competencias a adquirir e executar respecto as dificultades de aprendizaxe encontradas.

PALABRAS CLAVE: enfermería, estudantes, aprendizaxe clínico, pedagoxía narrativa 


\section{CITA RECOMENDADA:}

Movilla-Fernández, M.J.; Rodríguez-Maseda, E.; Freijomil-Vázquez, C.; Fernández-Basanta, S. (2019): A pedagoxía narrativa como elemento de avaliación da aprendizaxe clínica no grao de Enfermaría. En De la Torre Fernández, E. (ed.) (2019). Contextos universitarios transformadores: construíndo espazos de aprendizaxe. III Xornadas de Innovación Docente. Cufie. Universidade da Coruña. A Coruña (pág. 255-268).

DOI capítulo: https://doi.org/10.17979/spudc.9788497497121.255

DOI libro: https://doi.org/10.17979/spudc.9788497497121

\section{ABSTRACT}

Narrative pedagogy is used in the subject of Practicum of Nursing Degree. Students write 3 entries of a reflective diary about the experiences of learning in clinical setting. During the year 2017/2018, a group of Practicum teachers had the aim of identifying elements that students experience as relevant in their reflective diary entries in relation to their clinical learning. A qualitative analysis of the speech of the entries in the reflective diary of 20 students was carried out. The categories that emerged were: "negative learning experiences", "positive learning experiences" and "wanting to learn versus learning without learning". We conclude that the narratives of the students' experiences inform about aspects that affect their learning. These results allow to improve the process of learning and evaluation, when comparing the competences to acquire and execute with respect to the learning difficulties encountered.

KEY WORDS: Nursing, students, clinical learning, narrative pedagogy 


\section{INTRODUCCIÓN}

A formación en enfermaría ven a sufrir importantes cambios, por isto, a pedagoxía tradicional, centrada nos resultados, evidenciouse como insuficiente para asegurar un proceso de aprendizaxe de calidade (Emerson, 2007; Papastavrou et al., 2010). Isto é especialmente certo no entorno de aprendizaxe clínica, onde a teoría literalmente está viva (Medina-Moya, 2005). Como resposta xorden diferentes pedagoxías que son utilizadas nas Facultades de Enfermaría de todo 0 mundo (Siles-González y Solano-Ruiz, 2009). Unha das máis representativas é a pedagoxía narrativa, usada por profesores, estudantes e clínicos para compartir as súas historias experimentadas na tentativa de enxendrar un aumento do entendemento (Billings y Halstead, 2009; Emerson, 2007).

0 título de Grao en Enfermaría da UDC conta ca materia Practicum (24 ECTS) en $2^{0}$ cuadrimestre de $4^{0}$ curso, nela os estudantes realizan 4 meses de aprendizaxe clínica en entorno real (Centros de Atención Primaria, Hospitais, Residencias Maiores, etc....), a tutela é feita por un/unha profesional da enfermería en colaboración cun profesor/a da UDC.

A avaliación é moi complexa (Durante-Montiel, et al, 2012), está estruturada en unha avaliación por competencias que leva acabo o/a titor/a clínico en 2 momentos (intermedio e final) e por un diario reflexivo que traballa os estudantes co/ca profesor/a da Universidade. Para avaliar este diario e uniformar criterios entre todos os profesores emprégase unha rúbrica.

\section{DESCRICIÓN DA EXPERIENCIA}

Durante 0 curso 2017/2018, un grupo de profesoras de esta materia platexámonos 0 obxectivo de identificar elementos que os estudantes experimentan como relevantes nas súas entradas no diario reflexivo no relativo a súa aprendizaxe clínica no momento do Practicum.

Fixemos isto ca intención de que o proceso da pedagoxía narrativa fose circular, é dicir, que as experiencias dos estudantes nos informasen dos elementos críticos da aprendizaxe a traballar dende a posición de profesor e para poder incorporalos na avaliación. 
Empregouse unha análise cualitativa do discurso das tres entradas no diario reflexivo de 20 estudantes e da súa evolución tras recibir o feedback que lles demos con cada entrada.

\section{RESULTADOS}

Os 20 estudantes distribuíronse por diferentes servizos, visíbeis na táboa 1.

Táboa 1. Servizos de rotación dos estudantes

\begin{tabular}{|c|c|c|c|c|c|c|c|c|c|c|}
\cline { 2 - 10 } \multicolumn{1}{c|}{} & \multicolumn{8}{|c|}{ Servizos } \\
\cline { 2 - 11 } & \multirow{2}{*}{ AP } & \multicolumn{9}{c|}{ AE } \\
\cline { 2 - 10 } & \multirow{2}{*}{ CS } & UCI & HADO & Qx & REA & Urx & MI & Cx & Onco & Toco \\
\hline Alumnos & 2 & 5 & 1 & 2 & 1 & 3 & 4 & 1 & 1 & 1 \\
\hline
\end{tabular}

Abreviaturas AP: Atención primaria; AE: Atención especializada; CS: Centro de saúde; UCl: Unidade de coidados intensivos; HADO: Hospitalización a domicilio; Qx: Quirófano; REA: Reanimación; Urx: Urxencias; MI: Medicina interna; Cx: Ciruxía; Onco: Oncoloxía; Toco: Tocoloxía

As categorías de significado que emerxeron do análise foron "Experiencias de aprendizaxe negativas", "Experiencias de aprendizaxe positivas" e "Querer aprender versus aprender sen querer".

\section{Experiencias de aprendizaxe negativas:}

Esta categoría fai referencia a aquelas experiencias identificados polos alumnos que son prexudiciais para a súa aprendizaxe. Neste punto encóntranse os sentimentos que viven os estudantes, as dificultades que se atopan e as situacións non resoltas da súa aprendizaxe.

Un sentimento común que viven os estudantes é o medo. Os estudantes teñen medo a fallar ante un procedemento, a danar ós pacientes e a non estar a altura das expectativas do titor clínico. A base disto radica na súa percepción de falta de destrezas, como pode ser a falta de destreza para comunicarse cos pacientes. A parte do medo, algún estudantes son auto- 
esixentes consigo mesmo, o que da lugar a que comentan erros na súa práctica asistencial e que xurdan sentimentos como frustración e impotencia.

"pero muchas veces también tengo miedo a equivocarme en las decisiones que tengo que tomar o a no responder bien ciertas cuestiones que me plantea la enfermera. Quiero aprender lo máximo posible y me da un poco de miedo no contestarle de la manera que ella espera o no hacer bien todo lo que me pide." [D9_1DR]

Por outro lado, os estudantes presentan unha serie de dificultades que inflúen na súa aprendizaxe. Estas refléxanse en:

- Na adquisición de destrezas debido as características do servicio no que realizan as prácticas, como pode ser a comunicación ou o manexo de emocións ante situacións de urxencia ou nos falecementos, ou a dificultade de adquirir a destreza de autonomía pola carga de traballo do servizo.

"Pero en los turnos de mañana actualmente lo veo imposible [ser autónoma], soy lenta en muchas cosas como por ejemplo sacar la medicación, me paro mucho a mirar si el tratamiento es condicional, comprobar la dosis..." [D15_1DR]

- Ó realizar técnicas ou procedementos, xa que perciben en moitos casos presión ou nerviosismo tanto polos pacientes como polos familiares á hora de realizar unha técnica. Ademais, os estudantes teñen moitas dúbidas na realización de técnicas. Isto débese a variabilidade presente no como proceder, a auto-esixencia de querelo facer perfecto, falta de coñecementos, inseguridade e vergoña. Estas dificultades son mais acusadas nas primeiras etapas do rotatorio. Os estudantes describen que eses erros que xorden 0 inicio das prácticas son debidos a unha falta de concentración, nerviosismo dos estudantes, por no levar un organización adecuada, entre outros. "Por último, mencionar que la diferencia de color del uniforme del alumnado de prácticas con el del personal de enfermería supone que algunos pacientes se pongan 
en un estado de nerviosismo que dificulta llevar a cabo las técnicas de una manera adecuada." [D18_2DR]

- No manexo de sentimentos propios (como tristeza) durante as xornadas de prácticas e unha vez que chegan a casa, ou na separación do aspecto persoal do profesional. "Pero sin duda el aspecto que más dificultad ha supuesto para mí en lo que llevo de practicum, no han sido ni las técnicas ni la educación sanitaria, sino el aprender a discernir entre lo profesional y lo personal. Es muy estrecha la línea que separa estos dos conceptos." [D6_2DR]

- Na relación con pacientes e/ou familias: Dificultades en como actuar, comunicarse, empatizar e coñecer cal é o límite de implicación coa familia tras un falecemento ou en coidados paliativos, e na comunicación con pacientes críticos, agresivos (pacientes psiquiátricos, drogo dependentes, familiares desesperados), cun deterioro cognitivo alto, pacientes demandantes ou nenos; dificultade á hora de realizar educación sanitaria, no afrontamento dun ingreso dunha persoa coñecida para 0 estudante, ou afondar en aspectos psico-emocionais dos pacientes. Nalgúns casos, os alumnos perciben rexeitamento ou nerviosismo cando son atendidos por eles, chegando incluso a percibir racismo.

"[...] la actitud de algunos pacientes llega a ser una falta de respeto. A pesar de estar en un Hospital Universitario, tenemos que escuchar frases como "Tú a mí no me pinchas, que venga una enfermera", "Ya puedes pinchar bien", "Que mala suerte que ya me tocó una de prácticas", "itu tan cría que haces aquí?" o algo que nos quedó grabado que fue "fuisteis vosotras la que pinchasteis a mi mujer y le destrozasteis el brazo" [...]. Puedo entender cierta inseguridad al vernos como alumnas, pero nunca justifica las actitudes despectivas hacia nuestra labor en el hospital." [D18_3DR]

- Na relación co titor clínico (mala adaptación con el, a presión exercida sobre 0 estudante, ou os cambios repentinos de titor) e outros profesionais sanitarios (PS)) 
(dificultades na comunicación ou no traballo en equipo con outros PS, a falta de recoñecemento por un colectivo do equipo interdisciplinar do servizo, na relación con estudantes doutras universidades).

"Al principio me costaba un poco transmitir información a los médicos y residentes puesto que muchos de ellos se dirigían a mí de una forma un poco prepotente que me intimidaba." [D9_3DR]

- Tanto na resolución de problemas sinxelos no coidado como no manexo de situación críticas, dando lugar a frustración, impotencia e preocupación. Ademais, no día a día da práctica asistencial están en contacto con situacións altamente emotivas, aínda así os estudantes consideran fundamentais estas situacións para a súa aprendizaxe e adquisición de destrezas.

"Los problemas que surgen relacionados con el cuidado del paciente son numerosos, y a veces una simple llave cerrada de una de las luces del catéter central que en ese momento de nerviosismo tus ojos no llegan a identificar, suponen un disparo de múltiples alarmas. Algo sencillo que viéndote frente al cuidado del paciente se convierte en un estado de alerta y de frustración al no detectar cuál es el problema y poder así resolver la situación." [D2_2DR]

- Derivadas da tipoloxía das prácticas: Visibles nas dificultades de compaxinar a vida familiar, laboral e universitaria; dificultades na adaptación do horario.

"Adaptarse al cambio de turno es complicado, las mañanas y las tardes son Ilevaderas, sin embargo, las noches se hacen muy largas. La falta de costumbre hace que te entre el sueño con facilidad si no hay trabajo, además de la sensación de destemple, al estar inactivo y fuera del horario natural. El día siguiente a la noche el cansancio acumulado del día anterior pasa factura, manteniendo una sensación de agotamiento durante todo el día." [D21_1DR]. 
0 longo das prácticas, os estudantes experimentan situacións non resoltas de aprendizaxe como: Mal trato ou falta de humanidade dos PS ós pacientes, experimentación de accidentes laborais, erros e mala praxe na práctica asistencial polo estudante ou polos PS e convivencia nun entorno laboral con mal ambiente entre o persoal que traballa no mesmo.

"Debido a esto en algunos momentos me he sentido perdida a la hora de trabajar, por no saber que directrices seguir, cada persona tiene su criterio propio y hace presión para imponerlo. Además de esto, la posición de estudiante parece suponer que cualquiera está por encima de nosotros. Son muchas las ocasiones en las que me he sentido como la auxiliar de todo el personal. Sin voz ni voto, sin potestad de decidir si algo es correcto, simplemente siguiendo órdenes de otro." [D21_3DR]

\section{Experiencias de aprendizaxe positivas}

Esta categoría fai referencia a aquelas experiencias identificados polos estudantes beneficiosas para a súa aprendizaxe. Neste punto destacamos: Situación que motivan a aprendizaxe, adquisición de destrezas e o rol do titor clínico e outros PS.

En xeral, a Practicum é percibido polos estudantes como unha oportunidade de aprendizaxe única. Isto amplificase cando o estudante establece unha relación de confianza co seu titor clínico, convive nun ambiente de traballo positivo e conta coa empatía dos pacientes para poder desenrolar a práctica clínica.

"La oportunidad que nos ofrece el realizar el practicum es única y la calidad de la formación, en mi opinión, es excepcional." [D13_2DR]

Respecto a situación que motivan a aprendizaxe resaltan:

- Superación de retos persoais ou obxectivos, co fin de participar en procedementos máis complexos e lograr independencia profesional. "intento superarme día tras día para poder conseguir una formación excelente en quirófano y que me llenaría de orgullo, saber que he podido aprovechar cada hora de mi Practicum en aprender todo el conocimiento necesario para poder 
desempeñarme sin ayuda en caso de que algún día vuelva a trabajar en quirófano." [D1_2DR]

- A tipoloxía ou situación do paciente ou a gratitude e recoñecemento de pacientes e familiares

"quiero expresar como me ha afectado a nivel académico el ver la evolución de un paciente con úlceras varicosas ya que, al estar muy avanzadas, me he tenido que informar de cómo deberían ser unos cuidados apropiados y cómo tendría que enfrentarme a estas curas." [D10_1DR]

- 0 descoñecemento dun determinado tema de saúde

"Por otro lado, teniendo en cuenta las deficiencias de conocimientos en cuanto a los diferentes apósitos y cuándo utilizar cada uno de ellos a la hora de realizar curas, además de pedirle ayuda a mi tutor, también he tomado mis propias medidas." [D7_2DR]

- 0 tipo de prácticas e o servizo onde as realizan.

"Aunque se trata de una enfermera muy exigente y en algunas ocasiones me he sentido un poco agobiada, pienso que es una muy buena oportunidad de aprendizaje y eso me anima mucho a esforzarme y dar todo lo que esté en mi mano para conseguir buenos resultados y llegar a mis objetivos." [D9_1DR].

As destrezas son adquiridas polos estudantes a través de ser responsable dun paciente e participar no seu coidado, a participación en simulacros, experimentación de situacións de urxencia ou casos concretos, e o contacto con outros PS.

"El llevar a uno de los pacientes, el ocuparte de sus cuidados, de su estado en todo el turno... es una forma de sentir en tu propia piel la gran responsabilidad que tiene la enfermera. Para mí, que tu enfermera proporcione en ti toda su confianza en que lleves a uno de sus pacientes, con lo que eso conlleva en una unidad de cuidados 
intensivos es de agradecer y por otro lado fortalece en gran medida mi seguridad, mis conocimientos y mis actitudes como enfermera." [D2_3DR]

Os estudantes destacan tanto a adquisición de destrezas técnicas, relativas á medicación, como relativas ó coidado do paciente ou persoais, como organización, empatía e comunicación. Ademais, os estudantes destacan que realizar as prácticas nun determinado servizo beneficia a adquisición de destrezas que non serían adquiridas noutros. Estas destrezas son relativas a comunicación, coidado de diferentes tipos de pacientes, autonomía, e establecemento dunha alianza terapéutica con paciente e familia.

"En conclusión, de este mes, cada vez estoy más segura de haber escogido este Prácticum porque, aunque no sea un lugar de hospitalización, he aprendido valores que, en una planta, ya sea por la carga de trabajo y/o el tiempo que dedicaría a mis pacientes, no podría conseguir, como, por ejemplo, centrarme más en la esfera psicosocial del paciente y no solo en la biológica." [D10_2DR]

A medida que avanzan no rotatorio e o seu coñecemento aumenta, xorden sentimentos como: Seguridade, comodidade e autonomía.

"Cada vez es mayor la seguridad experimentada a la hora de trabajar al igual que la autonomía adquirida." [D21_2DR]

Finalmente, o titor clínico e o resto dos PS son fundamentais na aprendizaxe do estudante, porque fortalece os puntos débiles a través de soporte e o pensamento crítico do estudante, favorece oportunidades de aprendizaxe, a seguridade na práctica clínica e a eliminación de erros na práctica e na teoría; e facilita a adaptación o servizo e a adquisición de destrezas do estudante 0 darlle autonomía.

"En los turnos de noche (sobre todo) es cuando mi tutor me explica más cosas. Me ha dado muchos documentos sobre las Unidades de Cuidados Intensivos que me están ayudando mucho. Cuando tengo alguna duda y le pregunto, en vez de darme la respuesta me hace reflexionar para que sea capaz de encontrarla yo sola. Creo que 
eso es positivo porque así me esfuerzo y entiendo el conjunto de las cosas." [D3_1DR]

Isto e conseguido xa que 0 titor clínico aconsella, explica, resolve dúbidas, reforza positivamente 0 estudante, resolve situacións conflitivas da práctica asistencial, confía en el e é implicado na aprendizaxe. Ademais, a experiencia do titor clínico, a integración e recoñecemento do estudante dentro do equipo e a observación ó titor e outros PS favorece a aprendizaxe.

"Desde el primer momento observé con detalle lo que hacía la enfermera y lo que el primer día me parecía un mundo y muy dificultoso, poco a poco lo fui viendo como algo más sencillo que requiere de mucha práctica. Desde que empecé tuve la suerte de recibir muy buenas explicaciones con detalle por su parte, siempre haciéndome partícipe de los cuidados enfermeros y resolviendo todas mis dudas." [D9_1DR]

Aparte, os estudantes complementan a súa formación co estudo teórico, a través de información que buscan eles ou facilitada polo titor clínico. Isto é percibido como beneficioso, xa que lles axuda a superar medos.

"Me he informado de cómo realizarlas, he practicado por mi cuenta cómo debería realizarlas, como realizar la estimulación verbal, porque en realidad, la vergüenza que tenía se reduce a no saber estimular correctamente al paciente ya que explicarle la prueba una vez que te sabes información sobre ella, no es difícil." [D10_3DR]

\section{Querer aprender versus aprender sen quere}

Esta categoría fai referencia a aquelas experiencias vividas polos estudantes nas que, sen pretendelo, constitúen unha oportunidade de aprendizaxe. Nos diarios reflexivos son identificadas a través das reflexión que elaboran. Estas reflexión oriéntanse á asistencia que prestan e o rol do estudante e sobre os pacientes.

En canto a asistencia, resaltan a importancia da comunicación e a empatía cos pacientes e familiares, en moitos casos, facilitando o seu traballo con eles. Outros aspectos nos que 
reflexionan son: a importancia de proporcionar confort ós pacientes, que se traballe en equipo, valorar ó paciente de forma integral, incluír a familia na súa asistencia e proporcionar o mellor coidado. Este inclúe: Coidados para a adaptación a enfermidade, individualización dos coidados, rapidez na atención en situacións de urxencia, e a importancia da parte humana do coidado, que é máis que realizar técnicas sobre os pacientes.

"Trabajar con pacientes conscientes y orientados, que conocen su enfermedad terminal y el alcance de ella, hace que saquemos nuestra parte más cálida. Porque, aunque obviamente me falta mucha experiencia, he aprendido que lo más importante es aliviar su dolor." [D12_2DR]

Por outro lado, os estudantes reflexionan sobre o seu rol tanto na aprendizaxe como na asistencia. En canto a aprendizaxe, deben ser conscientes das súas limitacións e dificultades para poder mellorar e resaltan o desafío que ten adaptarse a un titor clínico. No relativo a asistencia, é importante ser minuciosos e coidadosos cos pacientes, non entorpecer a asistencia en situacións de emerxencia e manter unha actitude calmada nestas situacións urxentes.

"Como estudiante de enfermería, a pesar de las ganas de aprender a actuar en estas situaciones, debemos priorizar el respeto tanto a los profesionales que están trabajando como a los pacientes que se encuentran en esa situación. Debemos retirarnos si nuestra presencia puede entorpecer el trabajo." [D18_2DR]

Estas situacións e reflexións, favorecen a adquisición de destrezas como a empatía, a importancia do "coidado humano" máis que o "coidado técnico", seguridade no proceder de situacións de emerxencia, non xulgar ós pacientes e aprender a manexar a pacientes demandantes.

"Ben é certo que a parte practica e unha parte moi importante na nosa profesión, coñecer os procedementos, así como a correcta forma de aplicalos, pero este rotatorio serviume para aprender que como quizais erroneamente cheguei a pensar 
nalgún momento, nin moito menos esta e a parte máis importante da nosa profesión" [D8_3DR]

\section{CONCLUSIÓNS}

As narrativas das experiencias dos estudantes infórmanos sobre aspectos que condicionan a súa aprendizaxe, e que nos trasladamos a unha mellora do proceso de aprendizaxe e da avaliación, mediante a comparativa das competencias a adquirir e executar respecto as dificultades de aprendizaxe encontradas. Na seguinte táboa presentamos as dificultades experimentadas polos alumnos en relación coas competencias.

Táboa 2. Dificultades dos estudantes nas competencias de avaliación do Practicum

\begin{tabular}{|c|c|}
\hline Competencias & Dificultades \\
\hline $\begin{array}{l}\text { Competencia } \\
\text { comunicación/relación. Utilizar } \\
\text { estratexias e habilidades que permitan } \\
\text { unha comunicación efectiva con } \\
\text { pacientes, familias e grupos sociais, } \\
\text { así coma a expresión das súas } \\
\text { preocupacións e intereses. }\end{array}$ & $\begin{array}{l}\text { - Na adquisición da destreza comunicación debido a } \\
\text { idiosincrasia do servizo } \\
\text { - } \quad \text { Como actuar, comunicarse e empatizar coa familia } \\
\text { - Na comunicación con pacientes críticos, agresivos, } \\
\text { cun deterioro cognitivo alto, pacientes demandantes ou } \\
\text { nenos }\end{array}$ \\
\hline $\begin{array}{l}\text { Competencia proceso enfermeiro. } \\
\text { Aplicar o proceso de enfermaría para } \\
\text { proporcionar e garantir o benestar, a } \\
\text { calidade e a seguridade das persoas } \\
\text { atendidas }\end{array}$ & $\begin{array}{ll}\text { - } & \text { Mal trato ou falta de humanidade dos PS ós pacientes } \\
\text { - } & \text { Experimentación de accidentes laborais } \\
\text { - } & \text { Erros e mala praxe polo estudante ou polos PS }\end{array}$ \\
\hline $\begin{array}{l}\text { Competencia alteracións da saúde/ciclo } \\
\text { vital. Coñecer os problemas de saúde do } \\
\text { paciente, identificando as manifestacións } \\
\text { que aparecen nas distintas fases. }\end{array}$ & $\begin{array}{l}\text { - Na resolución de problemas sinxelos do coidado e no } \\
\text { manexo de situación críticas }\end{array}$ \\
\hline $\begin{array}{l}\text { Competencia técnicas e } \\
\text { procedemento. Realizar as técnicas e } \\
\text { procedementos de coidados de } \\
\text { enfermería, establecendo unha } \\
\text { relación terapéutica cos enfermos e } \\
\text { familiares. }\end{array}$ & $\begin{array}{l}\text { - } \quad \text { Presión ou nerviosismo polos pacientes e familiares. } \\
\text { - } \quad \text { Dúbidas na realización de técnicas pola: variabilidade } \\
\text { no como proceder, a auto-esixencia de querelo facer } \\
\text { ben, falta de coñecementos, inseguridade, vergoña e } \\
\text { falta de concentración, nerviosismo, mala } \\
\text { organización... }\end{array}$ \\
\hline
\end{tabular}




\begin{tabular}{|c|c|}
\hline $\begin{array}{l}\text { Competencia traballo en equipo. Ter } \\
\text { unha actitude cooperativa cos } \\
\text { diferentes membros do equipo } \\
\text { asistencial. }\end{array}$ & $\begin{array}{ll}\text { - } & \text { Na comunicación ou no traballo en equipo con outros } \\
\text { PS } & \text { Falta de recoñecemento dentro do equipo } \\
\text { interdisciplinario } \\
\text { - Na relación con estudantes doutras universidades. } \\
\text { - Convivencia nun entorno laboral con mal ambiente } \\
\text { entre o persoal que traballa no mesmo. }\end{array}$ \\
\hline $\begin{array}{l}\text { Competencia ética profesional. } \\
\text { Coñecer a lexislación aplicable e o } \\
\text { código ético e deontolóxico da } \\
\text { enfermería española, inspirado no } \\
\text { código europeo de ética e deontoloxía } \\
\text { de enfermaría. }\end{array}$ & $\begin{array}{ll}\text { - } & \text { Mal trato ou falta de humanidade dos PS } \\
\text { - } & \text { Erros e mala praxe polo estudante ou polos PS }\end{array}$ \\
\hline $\begin{array}{l}\text { Competencia relacional co/a titor/a. } \\
\text { Establecer unha relación de respecto } \\
\text { e de feed-back co/a seu/súa titor/a. }\end{array}$ & $\begin{array}{ll}\text { - } & \text { Mala adaptación } \\
\text { - } & \text { Presión exercida sobre o estudante } \\
\text { - } & \text { Cambios repentinos de titor. }\end{array}$ \\
\hline
\end{tabular}

\section{REFERENCIAS}

Billings, D. M., \& Halstead, J. A. (2009). Teaching in nursing: A guide for faculty. St. Louis, Missouri: Elsevier.

Durante Montiel, M. B. I., Lozano Sánchez, J. R., Martínez González, A., Morales López, S., \& Sánchez Mendiola, M. (2012). Evaluación de competencias en Ciencias de la Salud. México D.F: Editorial Médica Panamericana.

Emerson, R. J. (2007). Nursing education in the clinical setting. St. Louis, Missouri: Elsevier Medina Moya, J. L. (2005). Deseo de cuidar y voluntad de poder: la enseñanza de la enfermería. Barcelona: Edicions Universitat Barcelona.

Papastavrou, E., Lambrinou, E., Tsangari, H., Saarikoski, M., \& Leino-Kilpi, H. (2010). Student nurses experience of learning in the clinical environment. Nurse education in practice, 10(3), pp. 176-182.

Siles González, J., \& Solano-Ruiz, M. C. (2009). Antropología educativa de los cuidados: una etnografía del aula y las prácticas clínicas. Alicante: Marfil y Universidad de Alicante. 